\title{
Kentsel/Çevresel Sorun Kapsamında İklim Değişikliği İle Mücadelede Yeni Bir Yöntem: İnsansız Hava Arac1 (İHA)*
}

\author{
Baran Barış Aras ${ }^{1}$ \\ ORCID: 0000-0001-7791-8782
}

\section{Öz}

İklim değişikliği, içinde yaşayan canlılar dahil olmak üzere dünyanın her yerini etkileyen bir sorundur. Buradan hareketle iklim değişikliği ile mücadelede IHA'lar, hem bilim insanlarım hem de politika yapıcılarm ve yöneticilerin kentsel/çevresel sorunlarla mücadelede ve yaşam kalitesini artırmada iklim değişikliğine dair alternatif yöntemler oluşturmasına yardımcı olacaktır. IHHA'ları veri toplamak ve ekosistem değişikliklerini izlemek için kullanma firsatları stnırsız olup günümüzde bilim insanlarl, çiftçiler, politika yapıcılar ve diğer yöneticilerin, iklim dirençliliğini artıran çabalara sürekli gelişen IHA teknolojilerini uygulaması elzem bir ihtiyaç halini almıştır. Diğger bir ifade ile kentsel, kırsal ve kıyı topluluklarımızın sürdürülebilirliğini artırmak İHA gibi yeni teknolojilerin kullanımına bağlıdır. Keza, çalışmada iklim değişikliği ile mücadelede IH A kullanma potansiyeline, bu araçların nasıl uygulanacağına ve iklimi etkileyen alanlarda nasıl kullanıldıklarına değinilerek "İklim değişikliği ile mücadelede insansız hava araçlarını kullanmaktan nasıl yararlanılır?" araştırma sorusuna yoğunlaşılmıştır. Bu kapsamda IHHA'larn iklim değişikliğinin etkilerini ya da iklim değişikliğine etki eden etmenleri farklı ölçeklerde inceleme firsatı sundukları ve "Sürdürülebilir Kalkınma Hedefleri" kapsamında IHHA'ların, Să̆lık ve Kaliteli Yaşam; Sürdürülebilir Şehirler ve Topluluklar; Karasal Yaşam; İklim Eylemi" hedeflerine ulaşmada etkin birer araç oldukları sonucuna varılmıştır. Yine, IHA'ların insanlardan 10 kat daha hızl ă̆aç dikebildiğini, kamyonlardan \%23-54 daha az salınım yaptığını ortaya koyan çalışmalar da iklim değişikliği ile mücadelede bu sonucu pekiştirmiştir.

Anahtar Kelimeler: Drone, IHHA, Teknoloji, İklim Değişiklĭgi, Çevresel Sorun.

\footnotetext{
* Bu makale çalışması "5.Kent Araştırmaları Kongresi”nde bidiri olarak sunulmuştur.

${ }^{1}$ Doktora Öğrencisi, Dokuz Eylül Üniversitesi, E-mail: bb_aras.1992@hotmail.com

idealkent (c) Kent Araştırmaları Dergisi (Journal of Urban Studies)

http://idealkentdergisi.com

Geliş Tarihi Received Date: 30.10.2020 Kabul Tarihi Accepted Date: 14.04.2021
} 


\title{
A New Method In The Fight Against Climate Change Within The Scope Of Urban/Environmental Problem: Unmanned Aerial Vehicle (UAV)
}

\author{
Baran Barıș Aras ${ }^{2}$ \\ ORCID: 0000-0001-7791-8782
}

\begin{abstract}
Climate change is a problem that affects all parts of the World. As discussed in this study, in UAVs will help scientists, policy makers, administrators to create alternative ways of dealing with urban/environmental problems, improving the quality of life. The opportunities to use $U A V$ s are endless. Today, it has become a necessity for scientists, farmers, policy makers, other managers to apply ever-evolving UAV technologies to efforts to increase climate resilience. Increasing the sustainability of our urban, rural, coastal communities depends on the use of new technologies such as UAVs. Likewise, in the study, "How can we benefit from using unmanned aerial vehicles in combating climate change?" focused on the research question. And in the study, it was seen that UAVs offer the opportunity to examine the effects of climate change or the factors affecting climate change at different scales. And within the scope of "Sustainable Development Goals", it has been concluded that UAVs are effective tools in achieving the goals of "Good Health And Well-Being; Sustainable Cities and Communities; Life On Land; Climate Action". Likewise, studies that show that UAVs can plant trees 10 times faster than humans and emit 23-54\% less than trucks have also reinforced this result.
\end{abstract}

Keywords: Drone, UAV, Technology, Climate Change, Environmental Problem.

2 Doktora Öğrencisi, Dokuz Eylül Üniversitesi, E-mail: bb_aras.1992@hotmail.com

idealkent @ Kent Araştırmaları Dergisi (Journal of Urban Studies)

http://idealkentdergisi.com

Geliş Tarihi Received Date: 30.10.2020 Kabul Tarihi Accepted Date: 14.04.2021 


\section{Giriş}

Sanayi devrimi ile beraber atmosferde sera gazı yoğunluğunda gözlenen artış günümüzde nüfus artışı, endüstriyel faaliyetler, artan kentleşme ve yeşil alanların yok edilmesi ile de birleşerek dünyada iklim değişikliğine ve yaşam kalitesinin olumsuz etkilenmesine sebep olmaktadır. Günümüzde iklim değişikliğine dair araştırmalar büyük ölçüde çevresel verilerin ve numunelerin toplanmasına bağlıdır. Toplama yöntemleri doğada numunenin tipine bağlı olarak farklılık göstermekte olup bazı veriler araştırmacıların riskli ve/veya tehlikeli faaliyetler gerçekleştirmesini zorunlu kılmaktadır. Yeni teknolojilerin kullanımı ile örnek veri toplama için daha güvenli ve daha verimli alternatif yöntemler mümkün olabilmektedir.

İklim değişikliği, içinde yaşayan canlılar dahil olmak üzere dünyanın her yerini etkileyen bir sorundur. İster havada ister suda olsun, İHA'lar (insansız hava arac1) iklim değişikliğinin birçok zorluğuna çözüm bulmada önemli roller üstlenen bir araç olabilme potansiyeli taşımaktadır. İHA'ların iklim değişikliğine dair ana rolü, iklimde meydana gelen değiş̧iklikler hakkındaki bilgi ve anlayışımıza büyük katkı sağlayacak araştırma ve izleme çabalarını koordine etmek, uyumlaştırmak ve veri sağlamaktır.

Bu çalışma, başta iklim değişikliği olmak üzere kentsel ve çevresel sorunlarla mücadelede etkinlik sağlayan "IHA" teknolojisini tanıtarak günümüz şartlarına uyumlu ve mücadeleyi iyileştirici rolü olan alternatif bir araç göstermeyi amaçlamış olup "İklim değişikliği ile mücadelede insansız hava araçlarını kullanmaktan nasıl yararlanılır?" araştırma sorusuna yoğunlaşmıştır.

Bu bağlamda çalışmada ilk olarak insansız hava araçları tanımlanacak ve akabinde de bu araçların kullanım alanları hakkında genel bir bilgi verilecektir. İlerleyen başlıklarda da iklim değişikliğine değinilecek olup insansız hava araçlarının iklim değişikliği ile mücadelede kullanılmasına dair dünyada yapılmış çalışmalardan örnekler verilecektir. Sonuç kısmında ise insansız hava araçlarının iklim değişikliği konusunda genel kullanım alanları kısaca toparlanarak insanlı hava araçları ya da uydular karşısında avantajlı olduğu ve teknolojinin olumsuz yanlarının yanı sıra faydalarının olduğuna değinilerek bahsi geçen araçların "iklim değişikliği ile mücadelede kullanılıp kullanılamayacağı" değerlendirilecektir. 


\section{Yöntem}

Çalışmada, nitel yöntemler benimsenmekte olup doküman araştırması ve örnek olay kapsamında gerçekleştirilmiş çalışma ve araştırmalardan elde edilen sonuçlar 1şığında literatür de göz önünde bulundurularak iklim değişikliği gibi kentsel ve çevresel sorunlara karşı İHA teknolojilerinin günümüz şartlarına uyumlu ve mücadeleyi iyileştirici bir rol üstlenebilip üstlenemediği tartışılmıştır. Ele alınan araştırmalar ve uygulama örnekleri incelendiğinde İHA'ların iklim değişikliği ile mücadele konusundaki rollerinin "veri toplama; ağaç dikmek; atıkların azaltılması; teslimat ile ilgili emisyonların azaltılması; yenilenebilir enerji ekipmanlarının incelenmesi; vahşi yaşam hareketlerinin izlenmesi" gibi başlıklarla sınıflandırılabileceği görülmüş olup son olarak da bu araçların kentsel ya da çevresel sorunlar ile mücadele kapsamında alternatif bir araç olduğu belirtilmiştir.

\section{İnsansız Hava Araçları ve Kullanım Alanları}

Gelişen teknolojiyle birlikte, havacilık sektöründe de gelişmeler yaşanmış ve hava araçları çeşitlenmiştir (Yardımcı, 2019, s. 61). İnsansız hava araçları (IHHA) da hava araçları içerisinde kendine yer edinmiştir. İHA'ların askeri amaçlar dışında sivil kullanımlarının artması beraberinde bu araçların tanımlanması gerekliliğini ortaya çıkarmıştır (Özkan, 2016, s. 342). Günümüze kadar birçok devlet İHA'lar için hukuksal bir tanımlama ve düzenleme uğraşına girmiştir (NCSL, Erişim: 09.04.2019). Bu kapsamda, hükümetler sivil İHA'ların entegrasyonu için mevzuat düzenlemeleri yayınlamışlardır (Turza, 2014, s. 320). İHA'larla ilgili düzenlemeler, Uluslararası Sivil Havac1lık Organizasyonu (ICAO)'nun düzenleme ve kararları dikkate alınarak yapılmakta (Şikago Sözleşmesi, Erişim: 01.04.2019) olup 1944 tarihli Şikago Sözleşmesi olarak da bilinen Sivil Havacılık Sözleşmesinin İHÁlar ile ilgili kısmı 8. maddesinde yer almaktadır. Bahsi geçen sözleşmeye göre "içerisinde pilot olmadan uçabilme kabiliyetine sahip hava araçları" IHA olarak kabul edilmektedir (Dikmen, 2015, s. 155, Şikago Sözleşmesi, 1944, md.8).

İHA teknolojisi, askeri operasyonlarla beraber son 20 yılda benzeri görülmemiş bir büyüme seviyesi yakalamıştır (Valavanis ve Vachtsevanos, 2015, s. 94, 95). Diğer bir ifade ile İHA’ların gelişimi sivil amaçlı olmamıştır. Aksine askeri amaçlı İHA gelişmeleri, kullanılan teknolojiyi ucuzlatıp yaygınlaştırmış ve adeta bir domino etkisi ile sivil kullanım amaçlı talepleri artırarak kendine sivil bir İHA pazarı oluşturmuştur. Keza, 2020'nin sonunda İHA ulusla- 
rarası pazarının 80 milyar doları yakalayacağı ön görülmekte olup kısa vadede, sivil İHA pazarının en büyük payını dünya gözlem ve gözetiminin oluşturması beklenmektedir. Bu pazarda artan fursatlar, sivil uygulamalar için düşük maliyetli sistemler geliştiren küçük ve orta ölçekli çok sayıda işletmenin (KOBI) kurulmasına da yol açmıştır (Valavanis ve Vachtsevanos, 2015, s.99).

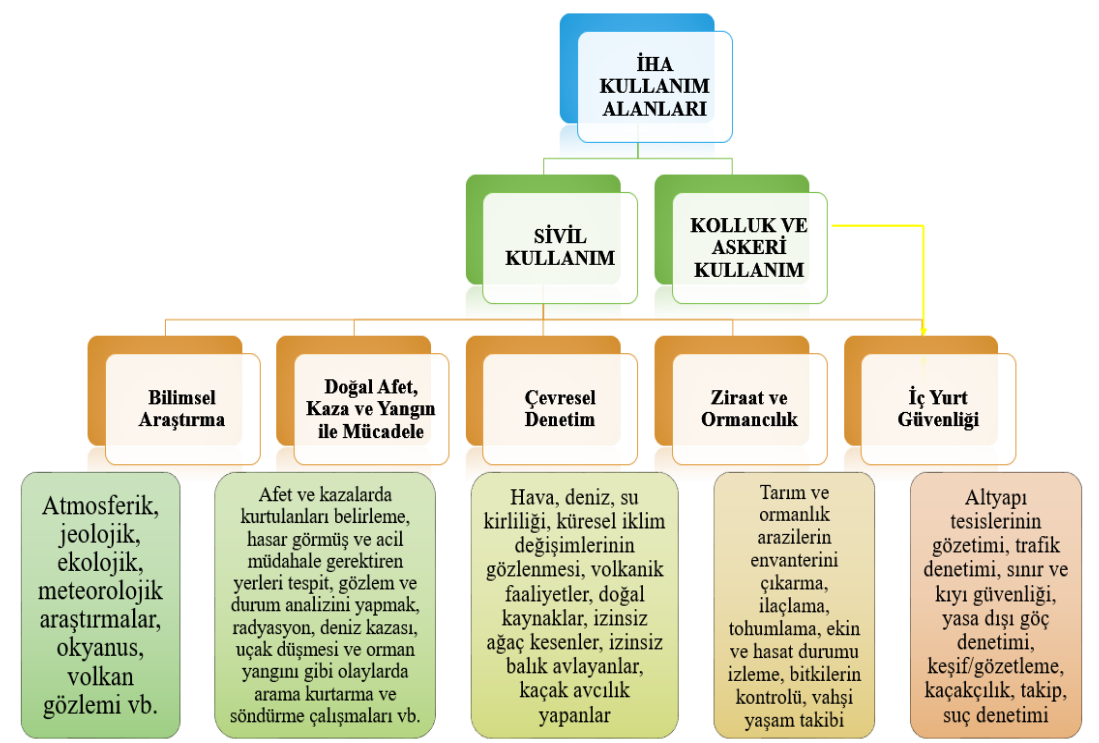

Şekil 1. İnsansız Hava Araçları Kullanım Alanları (Kaynak: Baştürk, 2015, s.82-85)

Şekil 1'den de görüleceği üzere İHA'ların kullanım alanları sivil ve askeri kullanım alanları olarak ikiye ayrılmaktadır. Askeri amaçlı İHA'ların kullanım alanları içerisinde keşif, gözetleme, elektronik savaş, mayın temizleme, hedef tespit ve ortadan kaldırma, istihbarat vb. konular bulunmakta olup bu çalışma askeri amaçlı IHHA'ları kapsamadığı için sivil kullanım alanlarına odaklanmak yerinde olacaktır. Sivil kullanım alanında ise Bilimsel Araştırma, Doğal Afet, Kaza ve Yangın ile Mücadele; Çevresel Denetim; Ziraat ve Ormancılık faaliyetlerinde İHA'ların kullanıldığı görülmektedir. Şekil 1'de iklim değişikliği ile doğrudan ve dolaylı mücadele anlamında İHA'ların kullanıldığı görülmektedir. Doğrudan mücadele anlamında bilimsel araştırmalar, çevresel denetimler ve yer yer ormancllık faaliyetleri gösterilebilirken dolaylı mücadele anlamında ise iklim değişikliği kaynaklı afetlerin izlenmesi ve bunlarla mücadele faaliyetleri gösterilebilir. 


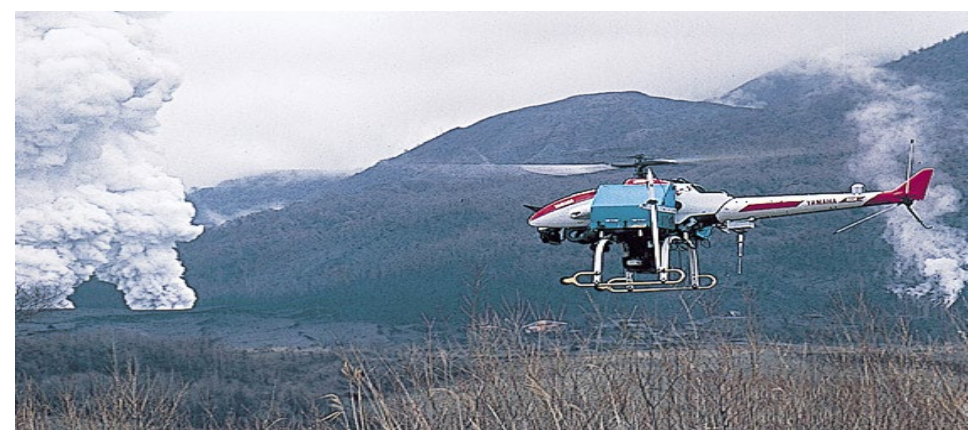

Şekil 2. Yamaha R-MAX Usu Volkanik Aktivitesini İncelerken (Yamaha Motor Global, https://global.yamaha-motor.com/about/ history/stories/0044.html).

Keza, Şekil 2'de de görüldüğ̈̈ üzere İHA'ların sivil kullanımına dair dünyada çok sayıda örnek vermek mümkündür. Bunlar arasında Arktik'i izlemek, depremlerden etkilenen alanları araştırmak, deniz memelilerini izlemek, sivil bilimsel araştırma veya çevresel izleme için kullanılan İHA'lar, hava / atmosferik veri toplama, oşinografik veri toplama, tarımsal izleme için konuşlandırılan İHA'lar Şekil 1' deki sivil kullanım alanları kapsamında verilebilecek örneklerden bazılarıdır (Valavanis ve Vachtsevanos, 2015, s. 100101).

\section{İklim Değişikliği İle Mücadelede İnsansız Hava Araçlarının Rolü}

İklim değişikliği, Hükümetlerarası İklim Değişikliği Paneli (IPCC) tarafından doğal ya da insan faaliyetlerinden kaynaklanan bir süreç sonunda oluşan iklimsel değişiklikler/bozukluklar olarak tanımlanmıştır (IPCC, 2018). BM İklim Değişikliği Çerçeve Sözleşmesi'ne bakıldığında da iklim değişikliği: “karşlaştırılabilir bir süreçte gözlemlenen iklimdeki doğal değişikliğin yanı sıra direkt veya dolaylı olarak atmosferin yapısına zarar veren insan faaliyetleri sonucunda meydana gelen iklimsel değişiklikler" olarak tanımlanmaktadır (UNFCCC, 1992, s.3). Yine, IPCC sera gazı etkisini: “Düşük dalgalı güneş ışınlarının üçte birinin atmosferden geri yansıyıp kalan üçte ikisinin de atmosfer tarafından emilmesi" olarak tanımlamıştır (Le Treut, Somerville, Cubasch, Ding, Mauritzen, Mokssit, Peterson, ve Prather, 2007, s.2).

İklim değişikliği doğal bir dengeye sahiptir ve sera gazlarının yoğunluklarındaki değişiklikler, küresel anlamda iklim dengesinin bozulmasi/değişmesi anlamına gelmektedir (Bahçeci, 2019, s.6). 2019 tarihli IPCC 5. Değerlendirme Raporu, iklim değişikliğine dair küresel verileri içerir. 1983 ile 2012 yılları arasında dünya sıcaklığında ortalama olarak $0,85^{\circ} \mathrm{C}^{\prime}$ lik $\left(0.65^{\circ} \mathrm{C}-\right.$ 
$1.06^{\circ} \mathrm{C}$ ) bir artış gözlenmiştir (IPCC, 2014b, s.2) Sicaklıktaki bu artışta \%95 oranında insan kaynaklı sera gazı emisyonları olduğu kabul edilmiştir (IPCC, 2014a, s.7). İklim değişikliği günümüzde de ayn hızda ilerlemeye devam ederse dünyada hava sıcaklığı 1990 - 2100 dönemi arasında mevcut sicaklıkların 2,50 C - 10,40 C arasında artacağı düşünülmektedir (Cass, 2006, s. 13). İklim değişikliğinde insan kaynaklı etkenlerin olduğu devletlerce de kabul edilmiştir. BM'nin 1992 tarihli İklim Değişikliği Çerçeve Sözleşmesi'nde taraf devletler, sözleşmeyi "atmosferdeki sera gazları yoğunluğunun insan aktiviteleri sonucu arttğı ve dolayısıyla da bu durumun sera etkisini artırarak dünyada sıcaklıklarda ortalama bir artışa sebep olacağı ve ekosistemlere ve canlılara zarar vereceğinden duyulan endişeyle" imzalamışlardır (UNFCCC, 1992, s. 3). Bu sözleşmeye ek olarak imzalanan 2016 tarihli Paris İklim Anlaşması'nı imzalayan taraf ülkeler, "iklim değişikliğinin insan toplumları ve ekosistemler için iklim değişikliğinin geri dönülmez bir boyut aldığından bahisle sözleşmeye taraf devletlerin geniş işbirliğini ve sera gazı salınımlarının minimize edilmesini hızlandırmak amaciyla katılımlarının önemini" kabul etmişlerdir (BM, 2015, s.2). Ayrıca, IPCC raporuna göre, “CO2 gazı 1750 2011 dönemlerinde en çok sera etkisi yaratan ışınımsal gaz" olarak kabul edilmiştir (IPCC, 2014a, s.4).

Sanayi devrimi ile beraber atmosferde sera gazı yoğunluğunda gözlenen artış, insan kaynaklı faaliyetler sonucu olmuştur. 1958 yılından beri yapılan atmosfer ölçümlerinde, atmosferde biriken sera gazlarının çok hızlı arttığı bilinmektedir. Sanayi Devrimi öncesinde ortalama 280 ppm (particul per million ya da milyonda bir parçacık) olan ortalama CO2 salınımı 1958 yılında ortalama 315 ppm'e kadar çıkmış olup 2012 yılında da ortalama 394 ppm'i görmüştür (Türkeş, 2012, s.4). 2017 yılında ise ortalama CO2 salınımı 405,5 ppm olarak kaydedilirken Şubat 2019'da bu değerler 410,6 ppm olarak kayitlara geçmiştir (Baltacı, 2019, s.21, 22). Güneş ışınlarının dünya atmosferindeki fazla birikmiş sera gazları sebebiyle dünyaya hapsedilip uzaya geri yansıyamaması küresel ısınmaya neden olmaktadır (Akın, 2006, s.32). Aşırı popülasyon artışı, endüstriyel faaliyetler, enerji tüketimindeki küresel artı̧, artan kentleşme, doğal yeşil alanların yok edilmesi ve bu sera etkisi yaratan gazların atmosfere kontrolsüzce salınması vb. faaliyetler, $\mathrm{CO} 2$ başta olmak üzere dünyada sera gazlarının yoğunluklarında meydana gelen artışların başlıca sebepleridir (Gazbir, Erişim: 20.05.2020, s. 1). İklimde meydan gelen değişiklikler ulusal değil, küreseldir. Bu nedenle küresel bir sorun teşkil eden iklim 
değişikliği ile mücadelede ülkelerin ekolojik dengeyi sağlayacak biçimde teknolojinin de yardımıyla dönüşümlerini gerektirmektedir (Baltacı, 2019, s. 24). İHA'lar bu gerekliliğge alternatif bir cevap oluşturmaktadır.

\section{İklim Değişikliği ile Mücadelede İHA'ların Kullanım Alanları ve Örnekleri}

Bu başlık kapsamında Monash Üniversitesinden Dr. Rohan Clarke'nin ve Lawrence Livermore Ulusal Laboratuvarından Joshuah Stolaroff'un sözlerinden faydalanmak asıl konumuz olan iklim değişikliği ile mücadelede İHÁların kullanım örneklerine geçmeden önce genel bir çerçeve oluşturabilmemiz açısından yerinde olacaktır:

"Bir ila iki gün süren bir hayvan araştırması şimdi bir saat içinde tamamlanabilmektedir. İHA görüntüleri bize emek yoğun geleneksel sistemle karşılaştırıldığında iklime ve zamana dayalı nüfus değişimi hakkında daha iyi bir fikir vermektedir." (Armstrong, 2019).

Dr. Rohan Clarke bu sözlerini, Avustralya'nın güney kıyılarının hemen dışında kalan Phillip Island'daki iklim değişikliğinin kürklü fok popülasyonu üzerindeki etkilerini izlemek amacıyla yaptıkları çalışmada İHA kullanımına ithafen söylemiştir. Her sene yapılmakta olan bu araştırmalar İHA kullanımına kadar geleneksel olarak el ile yapıldığından Clarke'nin de ifade ettiği gibi hem günler almakta hem de işlem tam olarak doğru bilgi sağlamamaktaydı. Ancak İHA'ların kullanımı ile birlikte bu araçların havadan gözlem yeteneği ve hayvanları tek tek etiketleyip takip edebilme kabiliyetleri sayesinde, fokların görüntüleri çok daha doğru şekilde çekilebilmiş ve sürüyü saymak ve iklim etkilerini gözlemlemek çok daha hızlı şekilde gerçekleştirilebilmiştir. Dolayısıyla da İHA'lar iklimsel değişimleri ve etkilerini anlamaya çalışan bilim adamları ve araştırmacılar için özellikle paha biçilmez bir alternatif olarak karşımıza çıkmaktadır (Armstrong, 2019).

Dr. Clarke'nin yanı sıra Lawrence Livermore Ulusal Laboratuvarından Joshuah Stolaroff ise şu sözleri sarf etmiştir:

“iHA'lar, özellikle şu anda ulaşımın en büyük kirletici sektörü olan nakliye emisyonları üzerinde önemli bir etki yaratabilir" (Armstrong, 2019).

Stolaroff ise bu sözü meslektaşları ile birlikte üç yılını ABD'de İHA'lar ve dizel motorlu teslimat kamyonları arasındaki çevresel farkları incelemek için yaptığı araştırmaya ithafen söylemiştir. Nature Communications'da yayınlanan bu araştırmada, İHA'ların 0,5 kg (1,1 lb)'lik hafif teslimatlarda 4 km'lik menzil içinde, paket başına ve kilometre başına kamyonlardan daha az enerji tükettiği görülmüştür. Bulgular, İHA'ların, dünya sera gazı emisyonlarının 
beşte birinden sorumlu olan taşımacılık sektörünün bir parçasını oluşturan kamyonlardan daha hızlı ve daha az çevresel etkiye sahip ürünler sunabileceğini göstermektedir. Stolaroff, "Bir İHA bir cep telefonu veya bir çift güneş gözlüğü teslim etmek için iyi bir seçenek olabilir." demiştir. Burada "hafif/küçük teslimat" ifadesi aklımızı karıştırmamalıdır. Keza Amazon, teslimatlarının büyük çoğunluğunu $2,5 \mathrm{~kg}$ 'dan daha hafif malların oluşturduğunu ve bunları taşımak için İHA’ları kullanmayı amaçladığını belirtimiştir. Aralık 2016' da, şirket ilk İHA'lı teslimatını gerçekleştirmiş ve İngiltere' deki bir müşteriye ürün tedarikinin 13 dakika sürdüğünü de açıklamıştır (Milman, 2018, Erişim: 07.11.2019). Yine başka bir çalışma da bazı durumlarda İHA kullanımının kamyon kullanmaktan daha az emisyon üreteceğini doğrulamıştır. Kaliforniya'da küçük bir paket teslimatı için bir İHA kullanılarak yapılan araştırmada, İHA'ların bir dizel kamyon kullanmaktan \% 54 daha az sera gazı emisyonu salınımı gerçekleştirdiği doğrulanmışken Missouri'de yapılan bir başka çalışmada da fark \% 23 olmuştur (Stolaroff, Samaras, O'Neill, Lubers, Mitchell ve Ceperley, 2018, s. 5; Hausfather, 2018, Erişim: 19.09.2020). Yine, konu hakkında Washington Üniversitesi de bir çalışma yapmış olup çalışmaya dair veriler bir tablo seti şeklinde Şekil 3'te gösterilmiştir. 
$10 \mathrm{Wh} / \mathrm{mi}$
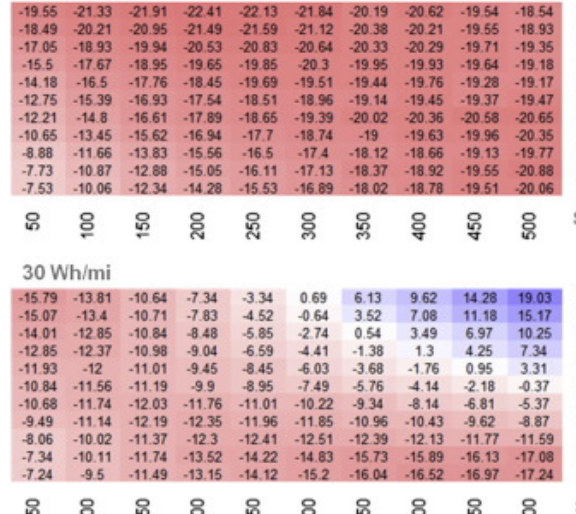

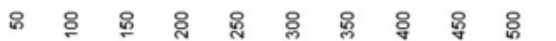

$50 \mathrm{Wh} / \mathrm{mi}$

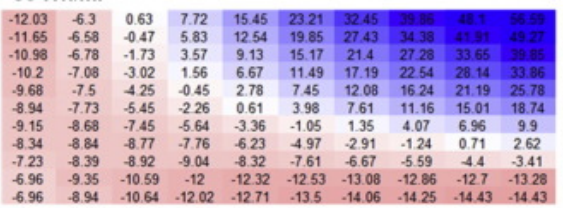

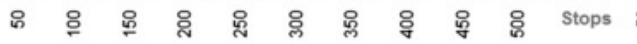

\section{$70 \mathrm{Wh} / \mathrm{mi}$}

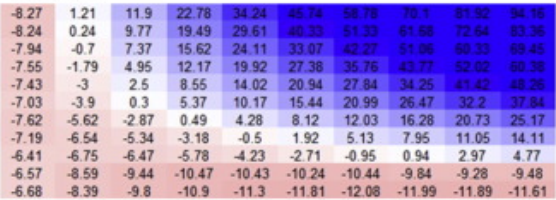

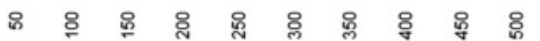

$90 \mathrm{Wh} / \mathrm{mi}$

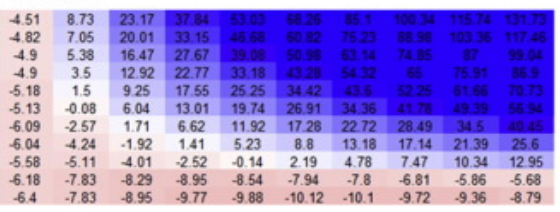

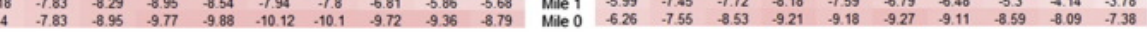

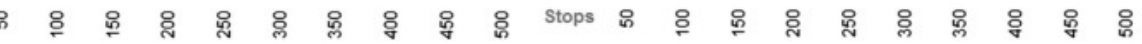

Şekil 3. Teslimat Kamyonu ile Teslimat İHA'larının CO2 Emisyonlarına Dair Washington Üniversitesinin Elde Ettiği Veriler

(Langston, 2017, https://www.washington.edu/news/2017/05/30/drone-vs-truckdeliveries-which-create-less-carbon-pollution/).

Yukarıdaki 1sı haritaları, bir İHA'nın enerji gereksinimleri (mil başına watt-saat olarak) ve bir rotadaki durak sayısı artışı olarak IHA ve kamyon teslimatları arasındaki karbondioksit emisyonu farklılıklarını göstermektedir. Kırmızı alanlar, insansız hava araçlarının kamyonlardan daha az karbon- 
dioksit yaydığı koşulları yansıtırken (daha hafif paketler, daha az duraklama); mavi alanlar ise insansız hava araçlarının daha fazla karbondioksit yaydığı (daha ağır paketler, daha fazla durak) koşulları ifade etmektedir. Dolayısıyla da kent içi gibi kısa mesafelerde ve belli kütlelere sahip kargoların taşınmasında İHA'ların CO2 emisyonlarını azaltabileceği ve dolaylı olarak da iklim değişikliği ile mücadelede bir araç olarak kullanılabileceklerini söylemek yanlış olmayacaktır.

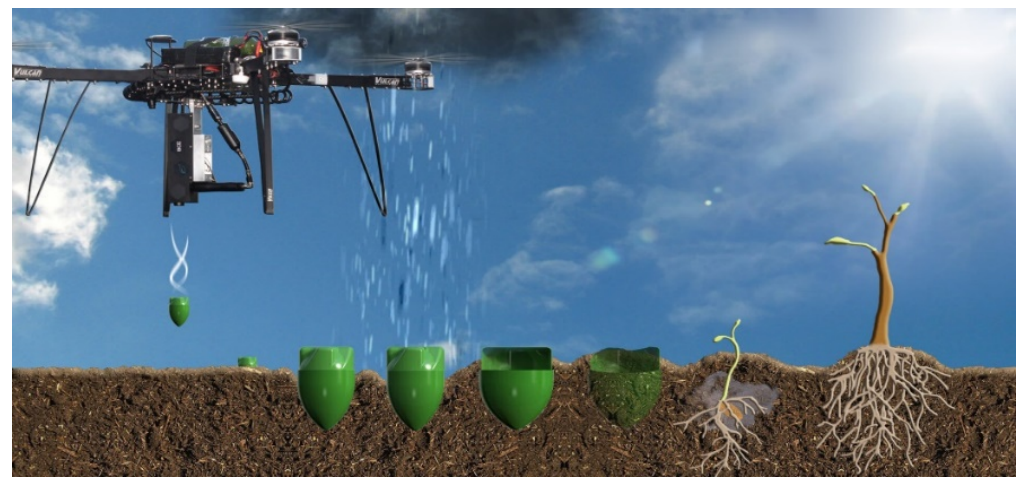

Şekil 4. Ağaç Dikiminde/Ekiminde İHA Kullanılması (Gayde, 2018)

Ayrıca, Şekil 4'ten de görüldüğü üzere İHA'lar ağaç dikmek/ekmek için de kullanılabilmektedirler. DroneSeed ve BioCarbon Engineering adlı şirketler havadan ağaç ekebilecek/dikebilecek İHA'lar geliştirmiştir. Bu İHA'lar üzerlerine monte edilmiş özel bir sistem vasıtasıyla yaklaşık 300 adetlik tohum kapsülünü taşıyabilmekte ve bu tohum yüklü kapsülleri toprağa doğru fırlatarak yaklaşık on sekiz dakika gibi kısa bir sürede aşağı yukarı bir hektarlık bölgeyi ağaçlandırabilmektedirler. Bu araçlar her bir tohumu bir saniye gibi sürede ateşleyerek günde yüz bin adet ağacın ekimini/dikimini gerçekleştirebilmektedirler. Geliştirilen bu sistemin elle yapılan ekim/dikim yöntemi ile kıyaslandığında ortalama on kat daha hızlı olduğu ve maliyetlerde de ortalama yüzde yirmi tasarruf sağladığı sistemi tasarlayan mühendisler tarafından ifade edilmektedir (Ünlü, 2017; DroneTürk, 2018). Dolayısıyla da iklim değişikliği ile mücadele açısından bu ağaç dikimi karbon oranını azaltarak, hava ve su kalitesini iyileştirerek ve erozyonu önleyerek iklim değişikliğini ve diğer çevresel zararları yavaşlatacaktır. Görüleceği üzere iklim değişikliği ile mücadelede bahsedilen bu ormanlaştırma metodu İHA'lar vasıtasıyla hizlandırılarak hem daha etkili hem de daha etkin olarak uygulanabilecektir. 
İHA'lar gelinen noktada karbon emisyonların azaltmak, vahşi yaşam popülasyonundaki değişiklikleri takip etmek ve örnek toplamak için her türden faaliyete uygundurlar. İHA'lar mükemmel bir veri toplayıcısıdır. Belki de İHA'ların iklim değişikliğiyle mücadeleye yardım etmelerinde en belirgin yöntem, veri toplanmasına yardımcı olmaktır. Bu minvalde İHA'lar, insanların kolayca gidemeyeceği yerlere seyahat ederek hem araştırma maliyetlerini azaltabilir hem de veri toplamanın doğruluğunu artırabilirler. Bu kabiliyetlerine dair alt başlıklar halinde dört örnek vermek çalışmanın temeli de olan iklim değişikliği ile mücadele kapsamında İHA'ların kullanılıp kullanılamayacağını anlamamıza yardımcı olacaktır.

\section{İnsansız Hava Aracına "Burun" ve "Beyin" Eklemek - Çin}

2016 yılında Çin'de, potansiyel kirletici faaliyetler İHA’lar vasıtasıyla fotoğraflanmakta ve çevre müfettişlerinin kişisel tecrübeleri ve deneyimleri doğrultusunda incelenmekte iken yapay zeka teknolojisinin de gelişmesi ile birlikte SciflyTech'in kurucusu Jiang Shutong, insansız hava araçlarına "burun" ve "beyin" yerleştirme fikrini ortaya atmış ve SciflyTech ve Guangdong IntelFlight UAV Ltd. tarafından ortaklaşa geliştirilen kirlilik tespit eden akıllı İHA'yı, 2017 başlarında Çin'de tanıtmıştır. Dongguan Çevre Koruma Bürosu'nun çevre izleme şube müdür yardımcısı Chen Baihui ise bu tanıtılan araç hakkında "Kirliliği tespit eden bir İHA'nın 60'tan fazla çevre müfettişinin işini yapabileceğini tahmin etmekteyim. Örneğin Zhancui Köyü'nün durumunu ele aldığımızda geleneksel soruşturmalar, altı kolluk kuvvetinin iki gün çalışmasını gerektirmektedir. Ve nihayetinde kirliliğin kaynağı bulunamayabilir" demiştir.

Chen Baihui'nin sözünden hareketle Zhancui Köyü'nde ne olduğuna bakmak yerinde olacaktır. Çin'in Guangdong eyaletindeki Zhancui'de bir köylünün kötü bir kokuyu yetkililere bildirmesinin ardından, Dongguan Şehrindeki çevre yetkilileri, bölgeye yüksek hassasiyetli sensörle donatılmış olan bu yeni İHA'yı göndermiştir. Bu İHA, bölgede uçucu organik kimyasallar, kükürt dioksit ve azot dioksit gibi sekiz hava kirleticisini tespit etmiştir. Ayrıca bu İHA sayesinde bölgedeki anormal uçucu organik kimyasal seviyelerini gösteren bir harita da hazırlanabilmiştir.

\section{Antropojenik İklim Değişikliği - Grönland}

Antropojenik iklim değişikliğinin Kuzey Kutbu'ndaki deniz buzu örtüsünde ve Grönland Buz Tabakasında kütle kaybını hızlandırdığı ve önemli bir azalma ile sonuçlandığı araştırmacılar ve bilim adamlarınca günümüzde 
sıkça dile getirilen bir meseledir. İkilim değişikliğinin deniz buzulları üzerindeki etkilerini ölçmek için yapılan geleneksel çalışmalar daha çok araştırmacılar tarafından buz kütleleri üzerinde yapılmaktadır. Dolayısıyla da deniz buzu kalınlığındaki ve deniz ekosistemleri üzerindeki ekolojik etkilerin azaltılması, kısmen sınırlı gözlemler nedeniyle günümüzde hala tam olarak anlaşılamamıştır. Son on yıllarda iklimdeki değişiklikler ise ne yazık ki ince deniz buzundan $(5-15 \mathrm{~cm})$ numune alma mecburiyetini doğurmuştur. Buzdağı örnekleri, helikopterler ve küçük tekneler kullanılarak ya da araştırmacıların bir buz baltasiyla bizzat buzul üzerinden parça toplamalarıla da elde edilebilir. Ancak iklim değişiklikleri nedeniyle Buzdağları, çok az bir etki ile veya hiçbir etki olmaksızın parçalanabildikleri ve / veya yuvarlanabildikleri için önemli bir güvenlik riski oluşturmaktadır. Benzer şekilde, buzulların incelmesi sonucu bu tabakalar çok daha kırılgan hale gelmiştir. Bu nedenle, buz örneği toplamak günümüzde hem lojistik açıdan zor hem de araştırmacılar açısından güvenlik riskleri teşkil eden faaliyetler olarak kabul edilmektedir. Bu sebeple iklim değişikliğinin buzullar üzerindeki etkilerine dair ortak anlayışımızı geliştirmek ve aynı zamanda bilim insanları ve destek gemileri için riskleri azaltmak amaciyla Aarhus Üniversitesinden Daniel Carlson ve ekibi tarafından yeni bir İHA tabanlı buz örnekleme platformu geliştirilmiştir (Carlson, Pasma, Jacobsen, Hansen, Thomsen, Lillethorup, Tirsgaard, Flytkjær, Melvad, Laufer, Lund-Hansen, Meire ve Rysgaard, 2019, s.1-2). IceDrone adını verdikleri bu İHA ile 10 metreyi aşan bir buzdağına iniş yapılabilmiş ve 800 gramlık bir numune alınabilmiştir. Örnek alındıktan sonra, IceDrone, görüntülerin yeterli örtüşmesini sağlamak için buzdağının etrafinda birkaç kez uçarak toplamda 223 görüntü çekmiş ve bu görüntüler, buzdağının yüksek çözünürlüklü bir 3D modelini oluşturmada kullanılabilmiştir (Carlson vd., 2019, s.5). 


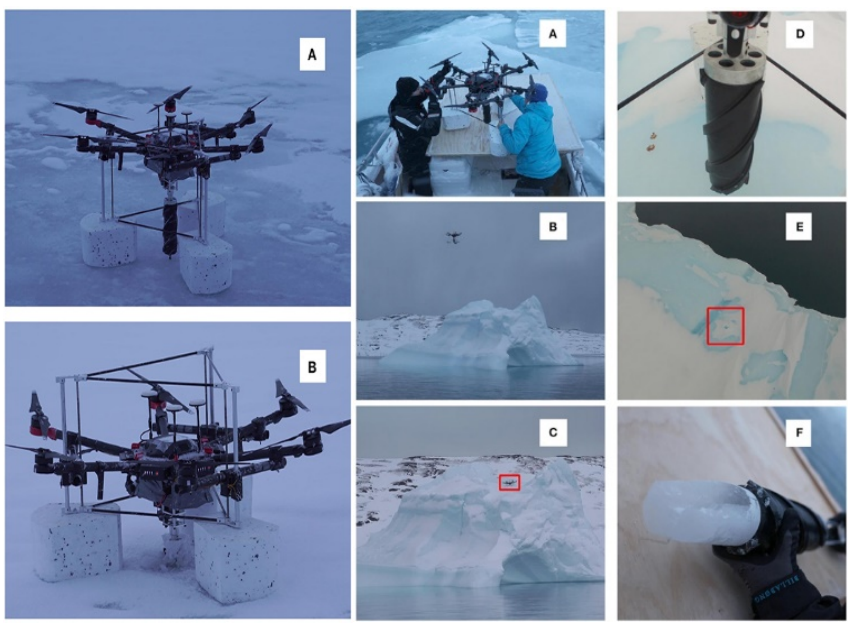

Şekil 5. IceDrone Çalışmasında Buz Örneği Alımı (Carlson vd., 2019, s. 8, 10)

İHA'larla toplanan numunelerden ise klorofil ve demir ölçümlerinin sağlıklı bir şekilde yapılabildiği ortaya konmuştur. Dolayısıyla da laboratuvar ve saha testleri, IceDrone'un buzuldaki sığ buz örneklerini bağımsız olarak alıp tutabildiğini göstermiş ve ince deniz buzundan numune alma girişimleri İHA sistemlerinin buz örnekleme operasyonlarına yardımcı olma potansiyelini göstermiştir (Carlson vd., 2019, s.12). IceDrone, buzdağlarının üzerinde bizzat çalışma ihtiyacını ortadan kaldırarak güvenliği artıııı bir araç olmuştur. Öte yandan IceDrone çalışması, başlangıçta buzdağları düşünülerek geliştirilmiş olsa da İHA'ların, ince deniz buzu ve buzullar gibi diğer potansiyel olarak tehlikeli ortamlardan örnekler elde etmek için de kullanılabileceğini ve büyük ölçekli iklim izleme programlarında kullanılabileceğini göstermektedir.

\section{İklim Değişikliği Kapsamında Hava Kirleticilerinin Analizi ve 3D Görselleştirilmesi -Yunanistan}

Yunanistan'da yapılmış bir çalışma da iklim değişikliği ile mücadelede İHA'ların kullanılabileceğini göstermiştir. Bu çalışmaya göre Yunanistan'da İklim Değişikliği, son on yılda ciddi bir çevre sorunu olmuştur. Şehirlerin hızlı ve düzensiz kentleşmesi, altyapı eksikliği ve kentsel bölgelerde artan motorlu araç filosu, ülkedeki hava kalitesinin bozulmasının ana nedenleri olmuş ve bu durum iklim değişikliğini hızlandırmıştır. Bu kapsamda Girit Teknik Üniversitesi Endüstri Enerji ve Çevre Sistemleri Laboratuvarı'nda, kentsel alanlarda hava kirleticilerinin 3D görselleştirilmesi için veri toplayabilecek 
bir İHA geliştirilmiştir. Üniversitenin kampüsünde gerçekleştirilen çalışmanın sonucunda geliştirilen İHA'nın aşağıdakileri tespit edip ölçümleyebildiği görülmüştür (Libelium, 2019, Erişim: 19.09.2020):

- Hava Sicaklığı,

- Atmosferik Basınç,

- Nem,

- Karbon Monoksit (CO),

- Karbondioksit (CO2),

- Kükürt Dioksit (SO2),

- Ozon (O3),

- Azot Dioksit (NO2),

- Amonyak (NH3).

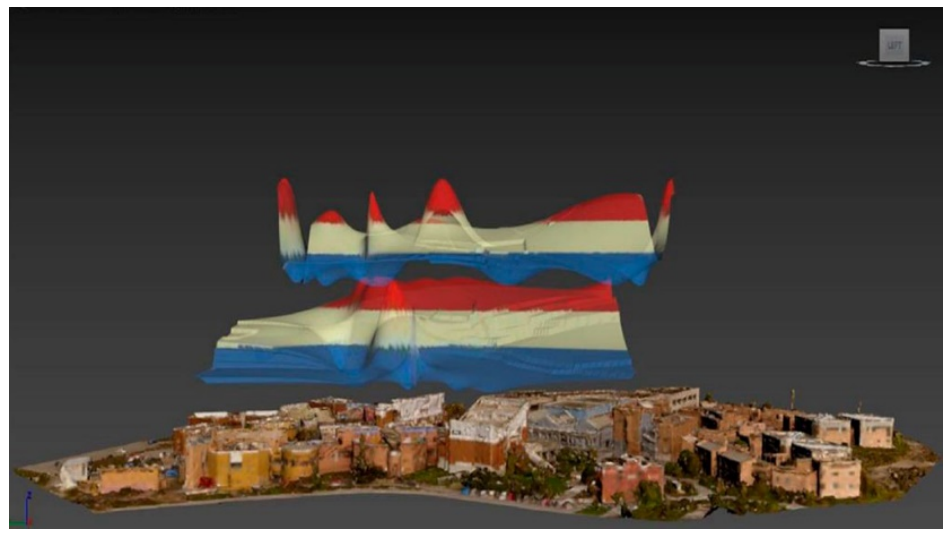

Şekil 6. Araştırma Sonucu İHA İle Elde Edilen $\mathrm{CO}_{2}$ Emisyonun 3D Ölçüm Haritası (Kaynak: Libelium, 2019, https://www.libelium.com/libeliumworld/success-stories/3d-air-quality-modeling-with-sensor-drones-in-greece/, Erişim: 19.09.2020).

Çalışma sonucunda sensörlerle donatılmış bu İHA'ların, izleme, sorun algılama ve yerel iklim kontrolü için lokal verileri elde edebildiği görülmüştür. Şekil 6'da da gösterildiği gibi İHA, çalışma alanının 3 boyutlu bir modelini oluşturulabilmiş ve hava kirleticilerinin dağılımını da coğrafi referanslı bu 3D model üzerinde görselleştirilebilmiştir. Hatta bu İHA, üniversite bacasından ve otoparkından $\mathrm{CO} 2$ salınımı olduğunu da tespit etmiştir. Bu çalışma bize göstermektedir ki, İHA'lar iklim değişikliğinin etkilerini ya da iklim değişikliğine etki eden etmenleri daha büyük ölçekte inceleme fırsatı sunabilecektir. Ayrıca, Şekil 7'de de gösterildiği gibi bu vaka çalışması, "Sürdürülebilir Kalkınma Hedefleri" kapsamında İHA’ların a)Sağlık ve Kaliteli Yaşam; b)Sür- 
dürülebilir Şehirler ve Topluluklar; c)Karasal Yaşam; d)İklim Eylemi” hedeflerine ulaşmada etkin birer araç olduğunu da ortaya koymuştur (Libelium, 2019, Erişim: 19.09.2020).

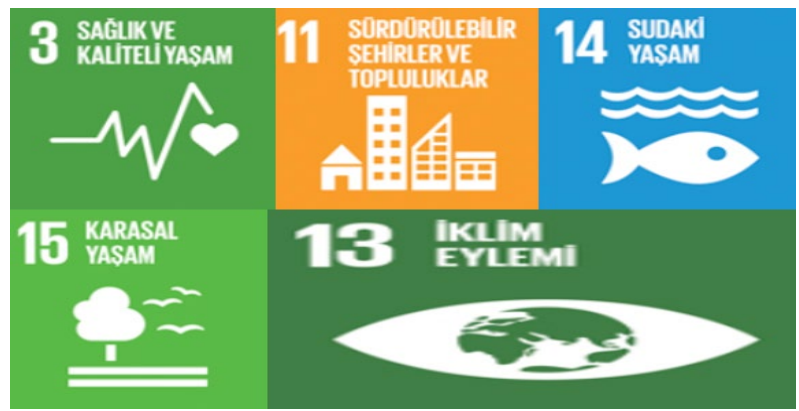

Şekil 7. Sürdürülebilir Kalkınma Hedefleri ve İHA'lar (UNDP, t.y).

\section{Evsel Kaynaklı Kirleticileri İzleme ve Tespit-İtalya}

Yunanistan'daki araştırmaya benzer bir biçimde İtalyan Araştırmacilar da Belluno' da hava kirliliği kontrolü ve tehlikeli ev emisyonlarını izlemek amacıyla uzaktan kumandalı İHA ve gelişmiş sensör teknolojisini kullanan TURIN adını verdikleri bir çalışma gerçekleştirmişlerdir. Çalışma sonucunda İHA'ların kontrol ünitelerine yerleştirilen sensörler sayesinde kirleticileri algılayabildiği ve 15 dakikalık bir uçuşla 10 hektarlık bir alanı haritalandırabildiği ortaya konulmuştur. Ayrıca, İHA'lara yerleştirilen sensörler sayesinde hem kirlilikle ilgili veriler elde edilmiş hem de kirlenmenin nereden geldiği de tespit edilebilmiştir (Zaccaria, 2019).

\section{Sonuç}

İklim konusu yalnızca atmosferik olaylarla sınırlı kalmamaktadır. Dolay1sıyla da yaşam kalitesinin birer parçası olan kent ve çevre unsurları iklim değişikliğinden etkilenmekte ve iklim değişikliğini de etkilemektedir. Bu konunun İHA ışığında yeniden ele alınması günümüzde bir gereklilik halini almıştır. İHA’ların iklim değişikliğine dair ana rolü, iklimde meydana gelen değişiklikler hakkındaki bilgi ve anlayışımıza büyük katkı sağlayacak araştırma ve izleme çabalarını koordine etmek, uyumlaştırmak ve veri sağlamaktır. Özetle, iklim değişikliği ile mücadelede İHÁların rol alacağı genel konuları "Kirlilik Tespiti, İzlenmesi, Takibi ve 2D/3D Haritalandırılması; Veri Toplama, Ormanlaştırma; Atıkların Azaltılması; Yenilenebilir Enerji Ekipmanlarının İncelenmesi (Bakım-Onarım-Denetim); Teslimat İle İlgili Emisyonların 
Azaltılması vb." olarak başlıklar halinde toparlamak mümkündür (Folk, 2019).

Her ne kadar, teknolojinin artmasıyla eşitsizliklerin ve kirliliğin arttığı düşüncesine odaklansak da gözden kaçırılmaması gereken asıl nokta suçun tek başına teknolojik gelişmelerde olmadığı gerçeğidir. Keza, teknolojiyi bir madalyon gibi görmek çok daha doğru olacaktır. Madalyonun bir yüzünde teknolojinin çevreye getirdiği olumsuzluklar bulunurken diğer yüzünde ise olumsuzluklarla mücadelede yine aynı teknolojinin kilit rolü bulunmaktadır. Ve hepsinden önemlisi ise bu madalyonun zincirinin "insanoğlunun" elinde olmasıdır. Diğer bir ifade ile çevre kirlenmesine asıl sebep olan etmen salt teknolojik gelişmeler değil bu teknolojiyi kullanan insanlardır. İnsanlar teknolojinin gelişmesi ile daha çok üretime odaklanmış ve daha çok kirletici faaliyetlerde bulunmuşlardır. "Sadece ve sadece üretmek" fikrine odaklanan insanoğlu ayn teknolojik gelişimi temiz ve çevreyi gözeten bir üretim modeline kanalize etmiş olsa idi bugün belki bu konuları konuşmuyor olacaktık. İşte bu anlamda devreye giren İHA'lar, çevreye insanın zarar veren yönünü azaltmaya odaklanarak belki de bu kötüye gidişatı yavaşlatacak bir araç olarak karşımıza çıkacaktır.

Sonuç olarak teknolojideki ilerlemeler ile beraber daha uygun fiyatlı ve manevra kabiliyeti artan İHA'ların günümüzde popülerlikleri artmaktadır. Bu gelişmeler sayesinde İHA'lar, araştırmacıların yüksek çözünürlüklü verileri doğruluk, hassasiyet ve kolaylıkla yakalamasına izin veren birer platforma dönüsserek çevremizdeki dünyanın nasıl değiştiğini ve bu değişikliği nasıl yönetebileceğimizi anlamak için değerli birer araç haline gelmiştir (Festa, 2018). Ancak tıpkı İHA'lara olan talebin artması gibi günümüzde Dünya' nın yüzeyi ile atmosfer arasındaki karmaşık etkileşimlerle ilgili belirsizlikler de artmıştır. İklim modellerini ilerletmek için gerekli istatistiksel bilgileri oluşturmak için uzak ve lojistik açıdan zor konumlardan değerli veriler gerekmektedir. Atmosferik araştırmacılar, insanlı uçaklar tarafından kolayca veya güvenli bir şekilde erişilemeyen yerlerde sık veya uzun süreli gözlemler gerektiren sorunları incelemek için insansız hava araçlarını kullanmaya yönelim göstermektedir. Keza, çoğu atmosfer araştırmacısı, karışık faz bulutlarının ve atmosferin termodinamik yapısının anlaşılmasında büyük bir boşluk olduğu ve insansız hava araçlarının bu boşluğa dair ihtiyaç duyulan verilerin çoğunu sağlayabileceği konusunda hemfikirdirler. Aynı şekilde ekolojistler de toprak nemini, yüzey sıcaklığını ve sıcaklık artışını avantajlı bir şekilde 
İHAS'tan da ölçülebilen anahtar değişkenler olarak tanımlamaktadırlar. Gerekli iklimsel gözlemler, İHAS için değiştirilebilen mevcut sensör teknolojisi kullanılarak uygulanabilmektedir.

Ayrıca, "Orta ve uzun vadeli atmosferik ve yüzey durumunun bölgesel olarak değerlendirilmesi ve bunların zamansal ve mekansal değişkenliği için iklim ölçeğinde gözlemler için gerekli mekansal çözünürlük ve gözlem uydular veya insanlı hava araçları ile de elde edilemez mi?" sorusu akla gelmektedir. Bu sorunun cevabı çok basit bir şekilde "Evet"tir. Fakat, uyduların istenilen lokasyonda olmadığı durumlarda gerekli lokasyona gelmesi birkaç gün alabilmekte ve oldukça maliyetli işlemler olarak kabul edilmektedir. İnsanlı hava araçlarında ise durum daha farklıdır. İnsanlı hava araçlarının uçuşa hazır olmaları için gereken zamanın görece uzun olması, tekrarlanan operasyonlara hızlı yanıt verememeleri, personel açısından mevcut riski, işletim maliyetleri ve yeterince alçak irtifa uçuş yapamamaları dolayısıyla ve günümüzde değiştirilebilen lens ve sensör teknolojileri de dikkate alındığında İHA'ların tercih edilmesi çok daha avantajlı gözükmektedir.

İklim değişikliğinin ve etkilerinin değerlendirmesi için gerekli olan veri kümeleri, birden fazla mevsim boyunca düzenli olarak ölçüm yapılmasını gerektirmektedir. Ivey, Verlinde, Petty, Ellingson ve Desilets (2013, s. vi-vii) 'in de belirttiği gibi bu tür veri setleri atmosferik ve yüzey durumlarının mevsimsel, yıllık ve mekansal değişkenliğini yakalayabilecek ve iklim değişikliği ile alternatif mücadele yöntemlerinin değerlendirmesini sunabilecektir. Bu gözlemler küçük insansız hava araçları tarafından en iyi şekilde yapılabilecektir. En kısa biçimde iklim değişikliğinin gözlenmesi ve iklim değişikliği ile mücadelede İHA teknolojileri, bölgenin uzaklığı ve insanlı hava misyonları için tehlikeli olan aşırı hava koşulları göz önüne alındığında araştırmacılara mücadele planı geliştirmek için stratejik bir firsat sunmakta olup karar vericiler ve politika yapıcılar için de yaşam kalitesini artırmada paha biçilemez veriler sağlayabilecek kabiliyetlere sahiptir.

İHA'ların yaşam kalitesini artırmada karar vericiler ve politika yapıcılara yol gösterici ve yardımcı bir araç oldukları görülse de tıpkı Avrupa ülkeleri ya da Amerika'da olduğu üzere Türkiye'de de bahsi geçen İHA teknolojilerinden haberdar olunmasına karşın askeri amaçlı İHA sistemlerine daha fazla odaklanıldığı görülmektedir. Türkiye'de sivil kullanım amaçlı insansız hava araçları hukuki açıdan da geri planda kalmakta ve üniversitelerin ya da bilimsel araştırma yapan kurumların çalışmaları için de herhangi bir sübvansiyon ya da teşvik sunulmamaktadır. Oysa Amerika Birleşik Devletleri, 2018 
FAA Yeniden Yetkilendirme Yasası kapsamında Sec.350 ile konuya dair yükseköğretim kurumlarında insansız hava aracı sistemlerinin kullanımını ele almış olup Sec.631 kapsamında da küçük insansız hava aracı sistemlerine dair okullarda eğitim programlarının açılmasına yasal zemin hazırlamaktadır (115th Congress, 2018, s.116,117,222). Öte yandan hukuki metinler göz önüne alındığında İHA'lar, Türkiye' de daha çok hava aracı gibi kabul edilmekte ve İnsansız Hava Aracı Sistemleri Mevzuatı (SHT İHA) ile Türk Sivil Havacılık Kanunu kapsamında değerlendirilmektedirler. Ancak başta Çevre Kanunu ve Orman Kanunu olmak üzere çevreyi ve kirlilikle mücadeleyi konu alan diğer hukuki metinlerde de İHA’lara dair doğrudan bir ifade yer almamaktadır. Bu doğrultuda Türkiye'nin konuya dair dünyadaki güncel olayları daha yakından takip etmesi ve kentsel/çevresel sorunlarla mücadelede kendini ispatlamış yöntemleri Türkiye koşullarında uyumlaştırma çabalarına hız katması gerekmektedir. Belediyeler başta olmak üzere gerek yerel düzeyde gerek de ulusal düzeyde kamu kurum ve kuruluşlarının konuya dair kapasiteleri artırılmalı ve kamu sektörü, özel sektör ve üniversite işbirliği -özellikle sivil İHA'lar ve kullanım alanları kapsamında- ön plana çıkarılarak gerekli teşvikler de sağlanmalıdır. 


\title{
Extended Abstract
}

\section{A New Method In The Fight Against Climate Change Within The Scope Of Urban/Environmental Problem: Unmanned Aerial Vehicle (UAV)}

$*$

\author{
Baran Barış Aras \\ ORCID: 0000-0001-7791-8782
}

The increase observed in the greenhouse gas density in the atmosphere with the industrial revolution, combined with population growth, industrial activities, increasing urbanization and destruction of green areas, causes climate changes and negative quality of life in the world. Today, research on climate change depends largely on the collection of environmental data and samples. Collection methods differ depending on the type of sample in nature and some data require researchers to carry out risky and / or dangerous activities. With the use of new technologies, safer and more efficient alternative methods are possible for sample data collection.

Climate change is a problem that affects every part of the world, including the organisms that live in it. Whether in the air or water, UAVs (unmanned aerial vehicles) have the potential to be a vehicle that plays an important role in finding solutions to many challenges of climate change. The main role of UAVs on climate change is to coordinate, harmonize and provide research and monitoring efforts that will contribute greatly to our knowledge and understanding of changes in climate. The role of UAVs in climate change is broad and there are different uses for facilitating data collection and obtaining results. Some of the general topics that UAVs will play in coping with climate change are as follows: "Data Collection; Planting a tree; Reducing Waste; Reducing Delivery Emissions; Investigation of Renewable Energy Equipment; Monitoring Wildlife Movements etc. "

With the information obtained with this technology, researchers can predict how certain climatic conditions have changed and how they can continue to change in the future. UAV technology helps us increase the flexibility of 
ecosystems in the face of changing climate. This type of technology will both allow urban and rural communities to better prepare for climate change and drought, and will help policy makers and managers plan for climate change to reduce their impact on people and nature and improve quality of life.

The opportunities to use UAVs to collect data and track ecosystem changes are unlimited, but scientists, farmers, policy makers, and other natural resource managers have become an essential need to apply ever-evolving UAV technologies to efforts to improve climate resilience. Increasing the sustainability of our urban, rural and coastal communities depends on the use of new technologies such as UAV.

The study adopts qualitative methods and the literature will also be considered in the light of the results obtained from studies and researches carried out within the scope of document research and case study. In this context, unmanned aerial vehicles were first described in the study. Afterwards, general information was given about the usage areas of these tools. In the following titles, climate change is mentioned, and examples of studies conducted in the world on the use of unmanned aerial vehicles in combating climate change are given. In the conclusion part, the general usage areas of unmanned aerial vehicles in terms of climate change are summarized briefly and it is stated that they are advantageous over manned aircraft or satellites and that technology has benefits as well as its negative aspects, and it has been shown whether the mentioned vehicles can be used in the fight against climate change. Likewise, the issue of climate is not limited to only atmospheric events. Therefore, urban and environmental elements, which are a part of quality of life, are affected by climate change and also affect climate change. It has become a necessity to reconsider this subject in the light of UAV.

In this study, it is aimed to show the UAVs that have a role to improve the fight against urban and environmental problems such as climate change and to present the potential of using UAV in combating climate change, how these tools will be applied and how they are used in areas that affect the climate. In this way, the quality of life will be improved and alternative methods can be developed and costs can be reduced in the fight. This goal is "How to use unmanned aerial vehicles in the fight against climate change?" It focuses on the research question.

Findings show that UAVs can deliver products faster and with less environmental impact than trucks that form part of the transport industry responsible for one-fifth of the world's greenhouse gas emissions. Another finding is that world observation and surveillance is expected to have the largest 
share of the civilian UAV market in the short term. Increased opportunities in this market have also led to the establishment of a large number of small and medium-sized enterprises (SMEs) developing low-cost systems for civil applications. Valuable data from remote and logistically difficult locations is required to generate the necessary statistical information to advance climate models. UAV technologies in monitoring climate change and combating climate change offer researchers a strategic opportunity to develop a combat plan, given the remoteness of the region and extreme weather conditions that are dangerous for manned air missions.

As a result of the study, it is seen that UAVs are more advantageous due to the relatively long time required for manned aircraft to be ready for flight, their inability to respond quickly to repeated operations, their risks, costs, and low altitude flight. In addition, UAVs offer the opportunity to examine the effects of climate change or the factors affecting climate change at different scales, and within the scope of the "Sustainable Development Goals", UAVs, Good Health And Well-Being; Sustainable Cities and Communities; Life On Land; It has been concluded that they are effective tools to achieve the "Climate Action" targets. Likewise, studies revealing that UAVs can plant trees 10 times faster than humans and emit 23-54\% less than trucks also reinforce the conclusion that UAVs can be an important tool in fighting climate change.

\section{Kaynakça/References}

115th Congress of the United States of America. (2018). FAA Reauthorization Act Of 2018. At The Second Session, PUBLIC LAW 115-254.

Akın, G. (2006). Küresel ısınma nedenleri ve sonuçları. Ankara Üniversitesi Dil Tarih Coğrafya Fakültesi Dergisi, 46(2), 29-43.

Armstrong, P. (2019). How drones help the environment and tackle climate change. 7 Kasım 2019 tarihinde https://www.verizon.com/about/our-company/fourthindustrial-revolution/how-drones-help-environment-and-tackle-climatechange adresinden erişildi.

Bahçeci, D. (2019). Kentsel alanda iklim değişikliği ile toplumsal temelli mücadele: Bir yöntem olarak kent bahçeleri. Yüksek Lisans Tezi, T.C. İstanbul Üniversitesi Sosyal Bilimler Enstitüsü Siyaset Bilimi ve Kamu Yönetimi Anabilim Dalı, İstanbul.

Baltacı, G. (2019). Küresel iklim değişikliği ve iklim değişikliği politikalarını etkileyen argümanlar. Yüksek Lisans Tezi, T.C. Selçuk Üniversitesi Sosyal Bilimler Enstitüsü Siyaset Bilimi ve Kamu Yönetimi Anabilim Dalı, Konya. 
Baştürk, R. (2015). Kolluk kuvvetlerinin istihbarat temininde başvurabileceği insansız hava araçları (iha) ve bu açıdan uygun iha özelliklerinin araştırılması. Yüksek Lisans Tezi, T.C. Harp Akademileri Stratejik Araştırmalar Enstitüsü, Uluslararası İlişkiler Ana Bilim Dalı, İstanbul.

BM. (2015). "Paris Agreement" 7 Kasim 2019 tarihinde https://unfccc.int/sites/default/files/english_paris_agreement.pdf adresinden erişildi.

Carlson, D. F., Pasma, J., Jacobsen, M. E., Hansen, M. H., Thomsen, S., Lillethorup, J. P., Tirsgaard, F. S., Flytkjær, A., Melvad, C., Laufer, K., Lund-Hansen, L. C., Meire, L. ve Rysgaard, S. (2019). Retrieval of 1ce samples using the ice drone. Frontiers in Earth Science, 7(287), 1-14.

Cass, L. R. (2006). The failures of american and european climate policy. State University of New York Press: Albany.

Choi, C. (2017). Fighting air pollution on the fly. 19 Eylül 2020 tarihinde https://insideunmannedsystems.com/fighting-air-pollution-fly/ adresinden erişildi.

Dikmen, M. (2015). İnsansız hava aracı (iha) sistemlerinin hava hukuku bakımından incelenmesi. The Journal of Defense Sciences, 14(1), 145-176.

DroneTürk. (2018). Özel geliştirilen dronelar, bir günde 100.000 ă̆aç ekebiliyor. 26 Ekim 2020 tarihinde https://droneturk.com.tr/drone-agac-ekimi/ adresinden erişildi.

Festa, D. (2018). 4 ways drones are helping people and nature prepare for climate change. 19 Mayıs 2020 tarihinde http://blogs.edf.org/growingreturns/2018/08/02/drones-climate-change-agriculture-wildlife-ecosystem-resilience/ adresinden erişildi.

Folk, E. (2019). 5 ways drones are impacting climate change. 7 Kasim 2019 tarihinde https://earthmaven.io/planetwatch/energy-economics/5-ways-drones-are-impacting-climate-change-lerpnFmyQkivLCCKwghHwA/ adresinden erişildi.

Gayde, W. (2018). New tree-planting drones can plant 100,000 trees in a single day. 26 Ekim 2020 tarihinde https://www.techspot.com/news/73032-new-tree-planting-drones-can-plant-100000-trees.html adresinden erişildi.

GAZBİR.(t.y). Karbon Emisyonu, Türkiye Doğal Gaz Dağıtıcıları Birliği Derneği Çalışması. $20 \quad$ Mart 2020 tarihinde https://www.google.com/url?sa=t\&rct=j\&q=\&esrc=s\&so-

urce $=$ web\&cd $=1 \& c a d=$ rja\&uact $=8 \& v e d=2$ ahUKEwj3z7iClML-

pAhXKxaYKHTcADi0QFjAAegQIAxAB\&url=https\%3A\%2F\%2Fwww.gazbir.org.tr\%2Fuploads\%2Fpage\%2FKarbon\%2520Emisyonu-RevSon.pdf\&usg=AOvVaw3li7DQOYKuMxUOAnmhYOXl adresinden erişildi.

Hanlon, M. (2004). Yamaha's RMAX - The World's most advanced non-military UAV. 14 Ocak 2020 tarihinde https://newatlas.com/go/2440/ adresinden erişildi.

Hausfather, Z. (2018). Small drones could be better for climate than delivery trucks, says study.19 Eylül 2020 tarihinde https:/www.carbonbrief.org/small-drones-could-be-better-forclimate-than-delivery-trucks-says-study adresinden erişildi. 
IPCC. (2014a).“Climate Change 2014: Synthesis Report”. Contribution of Working Groups I, II and III to the Fifth Assessment Report of the Intergovernmental Panel on Climate Change, Ed. By R.K. Pachauri and L.A. Meyer. IPCC, Geneva, Switzerland.

IPCC. (2014b). “2014: Summary for policymakers” Climate Change 2014: Impacts, Adaptation, and Vulnerability. Part A: Global and Sectoral Aspects. Contribution of Working Group II to the Fifth Assessment Report of the Intergovernmental Panel on Climate Change Ed. By Field, C.B., V.R. Barros, D.J. Dokken, K.J. Mach, M.D. Mastrandrea, T.E. Bilir, M. Chatterjee, K.L. Ebi, Y.O. Estrada, R.C. Genova, B. Girma, E.S. Kissel, A.N. Levy, S. MacCracken, P.R. Mastrandrea, and L.L.White, Cambridge University Press, Cambridge, United Kingdom and New York, NY, USA, 1-32.

IPCC. (2018) ."2018: Summary for Policymakers,” Global Warming of $1.5^{\circ} \mathrm{C}$. An IPCC Special Report on the impacts of global warming of $1.5^{\circ} \mathrm{C}$ above pre-industrial levels and related global greenhouse gas emission pathways, in the context of strengthening the global response to the threat of climate change, sustainable development, and efforts to eradicate poverty, Eds. Masson-Delmotte, V., P. Zhai, H.-O. Pörtner, D. Roberts, J. Skea, P.R. Shukla, A. Pirani, W. MoufoumaOkia, C. Péan, R. Pidcock, S. Connors, J.B.R. Matthews, Y. Chen, X. Zhou, M.I. Gomis, E. Lonnoy, Maycock, M. Tignor, and T. Waterfield, World Meteorological Organization, Geneva, Switzerland.

Ivey, M., Verlinde, J., Petty, R., Ellingson, R. ve Desilets, D. (2013). Polar research with unmanned aircraft and tethered balloons. A Report from the Planning and Operational Meeting on Polar Atmospheric Measurements Related to the U.S. Department of Energy ARM Program Using Small Unmanned Aircraft Systems and Tethered Balloons, Washington, D.C.

Langston, J. (2017). Drone vs. truck deliveries: Which create less carbon pollution? University of Washington. 19 Eylül 2020 tarihinde https://www.washington.edu/news/2017/05/30/drone-vs-truck-deliveries-which-create-less-carbonpollution/ adresinden erişildi.

Le Treut, H., Somerville, R., Cubasch, U., Ding, Y., Mauritzen, C., Mokssit, A., Peterson, T. ve Prather, M. (2007). "Historical Overview of Climate Change". Climate Change 2007: The Physical Science Basis. Contribution of Working Group I to the Fourth Assessment Report of the Intergovernmental Panel on Climate Change, Ed. By Solomon, S., D. Qin, M. Manning, Z. Chen, M. Marquis, K.B. Averyt, M. Tignor and H.L. Miller. Cambridge University Press, Cambridge, United Kingdom and New York, NY, USA.

Libelium. (2019). 3D Air Quality Modeling With Sensor Drones in Greece. 19 Eylül 2020 tarihinde https://www.libelium.com/libeliumworld/success-stories/3dair-quality-modeling-with-sensor-drones-in-greece/ adresinden erişildi. 
Milman, O. (2018). Express delivery: Use drones not trucks to cut carbon emissions, experts say. 7 Kasim 2019 tarihinde https://www.theguardian.com/environment/2018/feb/13/drones-trucks-climate-change-carbon-emissions adresinden erişildi.

Motley, J. L. (1860). History of the United Netherlands, 1584-1609, Complete. From the Death of William the Silent to the Twelve Year's Truce, vol. 1, New York and London: Harper and Brothers Publishers.

National Conference of State Legislators (NCSL). (t.y). Current unmanned aircraft state law landscape. 9 Nisan 2019 tarihinde http://www.ncsl.org/research/transportation/current-unmanned-aircraft-state-law-landscape.aspx adresinden erişildi.

O'Connell, R. L. (1989). Of arms and men: a History of war, weapons, and aggression. Oxford - New York: Oxford University Press.

Özkan, H. (2016). İnsansız hava araçlarının/drone'ların Türk Sivil Havacılık Hukukuna göre statüsü, unsurları ve ceza hukuku boyutuyla güncel sorunlar. Türkiye Barolar Birliği Dergisi, 125, 341-386.

Pakkan, B. ve M. Ermiş. (2010). “İnsansız Hava Araçlarının Genetik Algoritma Yöntemiyle Çoklu Hedeflere Planlanması". Havacılık ve Uzay Teknolojileri Dergisi, IV(3), 77-84.

Sato, A. (2003). The RMAX Helicopter UAV, YAMAHA MOTOR CO., LTD. 14 May1s 2019 tarihinde http://www.dtic.mil/cgibin/GetTRDoc?AD=ADA427393\&Location=U2\&doc=GetTRDoc.pdf adresinden erişildi.

Savunma Sanayi Müsteşarlığı (SSM). (2011). Türkiye insansız hava aracı sistemleri yol haritası (2011-2030). Uzay ve İnsansız Sistemler Daire Başkanlığı, DC Ankara.

Stolaroff, J. K., Samaras, C., O’Neill, E. R., Lubers, A., Mitchell, A. S. ve Ceperley, D. (2018). Energy use and life cycle greenhouse gas emissions of drones for commercial package delivery, Nature Communications, 9(409), 1-13.

Şahin, M. (2011). Sabit kanatlı mini insansız hava aracının geliştirilmesi ve ağaçlandırma çalışmalarında kullanımı. Yüksek Lisans Tezi. T.C. Erciyes Üniversitesi Fen Bilimleri Enstitüsü Sivil Havacılık Anabilim Dalı, Kayseri.

Şikago Sözleşmesi. (t.y). 1 Nisan 2019 tarihinde http://mevzuat.basbakanlik.gov.tr/ adresinden erişildi.

Turza, N. (2014). Dr. dronelove: how we should all learn stop worrying and love commercial drones. North Carolina Journal of Law E Technology, 15, 319- 361.

Türkeş, M. (2012). Türkiye de gözlenen ve öngörülen iklim değişikliği, kuraklık ve çölleşme. Ankara Üniversitesi Çevre Bilimleri Dergisi, 4(2), 1-32.

UNDP. (t.y). Sürdürülebilir kalkınma amaçları. 26 Ekim 2020 tarihinde https://www.tr.undp.org/content/turkey/tr/home/sustainable-developmentgoals.html adresinden erişildi.

UNFCCC. (1992). İklim değişikiği çerçeve sözleşmesi. 7 Kasım 2019 tarihinde https://unfccc.int/resource/docs/convkp/conveng.pdf adresinden erişildi. 
Ünlü, D. E. (2017). Günde 100 bin ağaç diken dronelar. Dunyacom, 19 Eylül 2020 tarihinde https://www.dunya.com/tekno-trend/gunde-100-bin-agac-dikendronelar-haberi-379032 adresinden erişildi.

Valavanis, K. P. ve Vachtsevanos, G. J. (2015). Military and civilian unmanned. Valavanis, K. P. ve Vachtsevanos, G. J. (Ed.), Handbook of Unmanned Aerial Vehicles: Aircraft içinde (s. 93-103). Dordrecht: Springer Science.

XinhuaNet. (2017). China focus: Drones fight pollution in Chinese manufacturing hub. 19 Eylül 2020 tarihinde http://www.xinhuanet.com/english/201709/05/c_136586310.htm adresinden erişildi.

Yamaha Motor Global. (t.y). 15 Ocak 2020 tarihinde https://global.yamaha-motor.com/about/history/ stories/0044.html adresinden erişildi.

Yardımcı, G. (2019). İnsansız hava araçlarına Türk mevzuatından bir bakış. Journal of Aviation, 3(1), 61-80.

Zaccaria, D. (2019). Italian researchers use drones to pinpoint air polluters. 18 Eylül 2020 tarihinde https://www.worldcrunch.com/tech-science/italian-researchers-use-drones-to-pinpoint-air-polluters adresinden erişildi. 